\title{
A ORIGEM DA MULHER-MARAVILHA EM NOVOS 52: DO PÓ VIESTE?
}

\section{THE ORIGIN OF WONDER WOMAN IN NEW 52: FROM DUST HAVE YOU COME?}

\section{EL ORIGEN DE LA MUJER MARAVILLA EN LOS NUEVOS 52: DEL POLVO HABÉIS VENIDO?}

\footnotetext{
${ }^{1}$ Mestranda em Ciências da Comunicação na Escola de Comunicaçôes e Artes - Universidade de São Paulo.
} 
PALAVRAS-CHAVE: Mulher-Maravilha; Histórias em quadrinhos; Novos 52.

KEYWORDS: Wonder Woman; Comics; New 52.

PALABRAS CLAVE: Mujer Maravilla; Historietas; Nuevos 52.

$\cos$

Conhecido como superaventura, o gênero que surgiu com o lançamento dos superheróis, teve início no final dos anos 1930, com a primeira aparição do Superman, seguido por Batman, em 1939 e pela Mulher-Maravilha em 1941. A Tríade da DC Comics inspirou o surgimento de uma série de outros super-heróis que seriam responsáveis por mudanças significativas no mercado editorial norte-americano. Para Reblin (2011, p.9), o gênero da superaventura é um reflexo cultural das transformaçóes sociais pelas quais os estadunidenses passaram e que, no fim dos anos 1930, caracterizavam-se por reverberaçóes da Grande Depressão de 1929 e da Primeira Guerra Mundial.

Em relação à Mulher-Maravilha, que teve em 2017 seu primeiro filme de longametragem produzido para os cinemas, não é possível dissociar a personagem do contexto em que ela foi concebida, afinal, ainda que em muitos aspectos ela possa parecer uma heroína que representa apenas uma versão feminina de um super-herói, as produções acadêmicas, bem como sua repercussão na mídia nos últimos meses, indicam que o seu apelo, principalmente junto ao público feminino, é significativo e merece atenção.

Por isso, entender como a personagem foi concebida é fundamental para que se possa discutir a questão de suas diversas origens ao longo de seus mais de 75 anos de existência e, para isso, não faltam livros sobre os diversos aspectos que envolvem o surgimento da Mulher-Maravilha. Muitos deles, nunca lançados no Brasil, sendo A História Secreta da Mulher-Maravilha uma das poucas exceções. Traduzido por Érico Assis, o livro de Jill Lepore (2017) investiga a vida de William Moulton Marston, criador da personagem. 
Para Lepore (2017), William Marston era um homem muito à frente de seu tempo: psicólogo que inventou o polígrafo, foi convidado por Max Gaines para ser consultor de sua editora, na época a $E C$ Comics, na tentativa de evitar controvérsias que começavam a surgir sobre a violência nos quadrinhos. Gaines conheceu Marston por meio de um artigo que o renomado psicólogo havia escrito em defesa das HQ. Marston, que já havia sido consultor da Universal Pictures, chamou H. G. Peter para desenhar a história de uma nova heroína, que, embora tenha alcançado sucesso entre homens e mulheres de diversas geraçóes tão logo foi lançada, carregava por trás de sua criação um passado tão controverso que, caso chegasse ao conhecimento de seus editores e de seu público, seria banida para sempre das bancas de jornais.

Lepore referia-se ao fato de que o psicólogo, além de ser casado com duas mulheres, Elizabeth Halloway e Olive Byrne, tinha forte ligação com o movimento sufragista, uma vez que Byrne era sobrinha de Margareth Sanger, uma enfermeira que abriu a primeira clínica de aborto nos EUA.

Controvérsias à parte, em seus 75 anos de história, a Mulher-Maravilha não só teve diversas fases, passando pela mão de diversos roteiristas e desenhistas, majoritariamente homens, como também seu papel social sofreu muita influência dos diversos contextos históricos pelos quais ela transitou: já foi considerada feminista, embaixadora da paz, ganhou cargo na ONU e depois foi removida, já foi símbolo sexual e hoje é bissexual.

Quando Marston criou Diana, em suas primeiras histórias não mencionava sua origem. No entanto, com a necessidade de justificar os poderes da super-heroína, seu autor pensou em algo que náo a colocasse como dependente de um homem para que pudesse existir, assim, em uma narrativa repleta de simbologia cristá, ela teria sido esculpida em barro, pela sua mãe Hipólita, a rainha da Amazonas, e sua vida e poderes teriam sido dádivas dos deuses do Olimpo, ou seja,

em tempos de guerra, a Mulher-Maravilha representava a força das mulheres norte-americanas, que deviam trabalhar para que seu país se mantivesse firme e unido enquanto os homens lutavam na guerra contra os nazistas e em nome da liberdade. Ela é a mulher que vai à luta pelos 
seus ideais e se sacrifica por eles, mas sem perder sua identidade feminina. (NOGUEIRA, 2015, p. 112)

Vivendo por milênios em Themyscira, uma ilha inalcançável aos homens, as Amazonas eram mulheres mitológicas que possuíam a proteção dos deuses, porém, devido a um acidente com um piloto que acaba caindo na ilha, colocando em risco a localização das Amazonas, elas criam jogos para que uma delas seja responsável em levá-lo de volta ao "mundo dos homens".

Essa narrativa, em que o principal motivo da ida de Diana para sociedade se justificava por meio de seu relacionamento romântico com o piloto Steve Trevor, foi explorada em quase todas as suas histórias, em que toda sua força e coragem costumavam ser apagadas em função da exibição exaustiva de seus dotes físicos. Ela chegou a ter seus poderes retirados e tornou-se uma dona de boutique nos anos 1960, retornando ao seu potencial mais heroico com a série de TV, exibida nos anos 1970.

Com o sucesso da série, houve o interesse da editora DC Comics em recuperar o prestígio da heroína entre os leitores e superar uma das crises que a indústria enfrentava, por isso, nos anos 1980, convidou George Perez para, mais uma vez, reiniciar a história da Mulher-Maravilha. Nessa versão, ela seguia sendo um milagre dos deuses que foi moldada do barro.

Porém, com o lançamento da série Novos 52, em 2011, escrito por Brian Azzarello e desenhado por Cliff Chiang, quando a $D C$ reiniciaria as histórias de 52 de seus heróis mais importantes, Diana teve sua origem modificada mais uma vez ${ }^{2}$, para que sua ascendência divina pudesse colocá-la como uma possível herdeira do Olimpo. Lançada em versão encadernada pela editora Panini em 2017, cada edição traz 7 histórias do total de 55 fascículos publicados nos EUA. Atualmente, foram lançadas apenas 23 histórias.

$\mathrm{Na}$ versão que também é apresentada em sua estreia nos cinemas, Diana é filha de uma relação entre Hipólita e Zeus, mas, ao menos nas primeiras ediçôes de Novos 52, a

\footnotetext{
${ }^{2}$ https://universomulhermaravilhadotcom.wordpress.com/2016/04/17/a-mulher-maravilha-dos-novos-52/
} 
princesa das Amazonas não desconfia de sua origem divina e acredita que tenha sido esculpida do barro.

Figura 1: Primeira página da ediçáo 0 - No covil do Minotauro - Novos 52
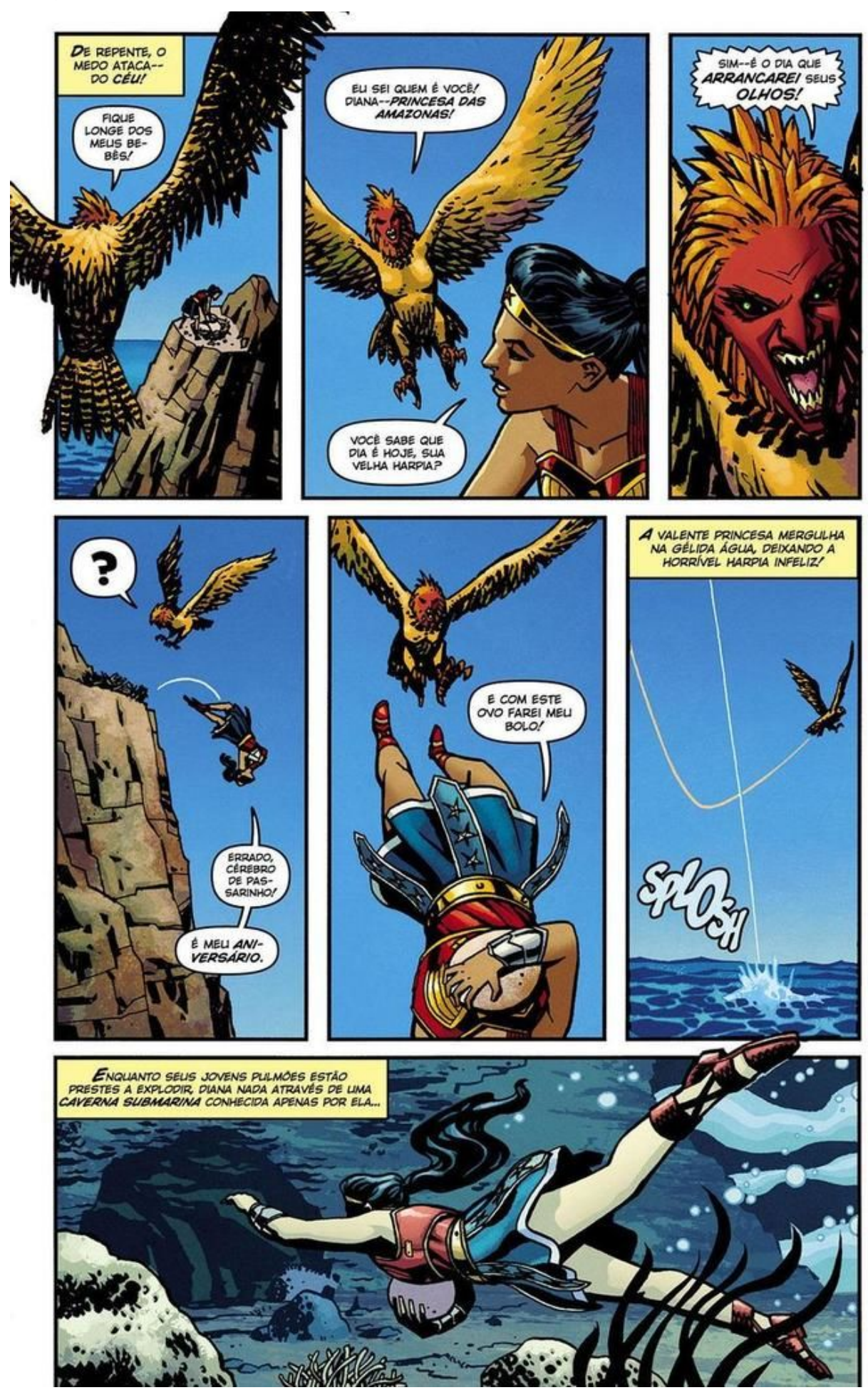
Hipólita mantém sua história em segredo por temer o que Hera poderia fazer com sua filha se descobrisse mais um filho bastardo de seu marido. Na mitologia grega, Hera é conhecida por punir severamente esses filhos que são frutos do adultério de Zeus. Então, a Mulher-Maravilha cresce acreditando ser diferente de suas irmãs e sofrendo bullying por isso.

A edição 0 , que foi trazida juntamente à número 13 no Brasil, mostra uma Diana adolescente, tendo que lidar com desafios para que sua nova idade seja reconhecida pela rainha. Em uma história cheia de aventuras, somos apresentados a uma jovem forte, disposta a feitos hercúleos para conseguir roubar um ovo de uma harpia gigante (Figura 1), para que assim, sua passagem de ano seja afirmada diante de todas as Amazonas e seu bolo de aniversário seja preparado.

Mas, mesmo se destacando entre as demais moradoras da ilha, Diana sente-se diferente e é tratada de forma diferente por algumas Amazonas, de maneira que ela mesma chega a se questionar sobre sua existência e seu lugar no mundo, oferecendo ao leitor uma leitura que se aprofunda nas reflexóes de uma personagem que, para muitas pessoas, limitase a certas características físicas tão difundidas popularmente.

A Diana de Novos 52 não veio do pó e sua herança genética não passou despercebida por Ares, Deus da guerra, que secretamente a treina e a ajuda a desenvolver sua autoconfiança e autoestima. Sua ligação com a mitologia grega revela-se, ainda, de forma mais acentuada quando seu teste final para ser reconhecida por Ares é lutar contra o Minotauro.

Então, em Novos 52, a relação das Amazonas com os deuses do Olimpo é amplamente explorada, propiciando ao leitor uma viagem onírica em companhia de vários filhos bastardos de Zeus e lidando com os caprichos e vaidades dos deuses e outros seres mitológicos que lembram os personagens encontrados na premiada série Sandman, pois não só a constituição física desses personagens é detalhada, como também seus aspectos psicológicos, nos levando a situaçóes de resoluções complexas. 
Essa retomada às suas origens mitológicas remonta ao que Umberto Eco afirma sobre as semelhanças e diferenças entre os super-heróis e os mitos:

Há, de fato, uma diferença fundamental entre uma figura como o Superman e figuras tradicionais como os heróis da mitologia clássica, nórdica, ou as figuras das religiōes reveladas. A imagem religiosa tradicional era de uma personagem de origem divina ou humana, que, na imagem, permanecia fixada nas suas características eternas e o seu acontecimento irreversível. Não se excluía que, por trás da personagem, existisse, além de um conjunto de características, uma estória: mas a estória já se achava definida segundo um desenvolvimento determinado e passava a constituir, de modo definitivo, a fisionomia da personagem.

(...) a personagem das estórias em quadrinhos nasce, ao contrário, no âmbito de uma civilização do romance. (...) a tradição romântica oferecenos uma narrativa em que o interesse principal do leitor é deslocado para a imprevisibilidade do que acontecerá, portanto, para a invenção do enredo que passa para o primeiro plano. (ECO, 1974, p. 259)

Portanto, ainda que nas histórias em quadrinhos a Mulher-Maravilha tenha sua origem recontada diversas vezes, muito de sua essência assemelha-se a narrativas mitológicas que conhecemos e continua apelando à nossa necessidade de lidar com a realidade por meio do que vivenciamos na ficção. O Diana de Novos 52 reflete muito bem um contexto em que a produção de seu filme, dirigido por uma mulher, foi possível. E se nos anos 1940 Marston acreditava que ela representava as mulheres de sua geração, é possível crer que a personagem encarna hoje os valores tâo difundidos pelos movimentos sociais e que buscam igualdade de direitos e de representatividade em diversos âmbitos da vida.

A ficção assinala que o contexto não é mais o mesmo de 75 anos atrás e que, se tivemos uma narrativa em que a protagonista é literalmente uma deusa, retratada de forma menos sexualizada do que ela costumava ser, é possível inferir que o mercado editorial dos quadrinhos também pode mudar e, quem sabe, tenhamos mais mulheres produzindo as histórias da heroína mais icônica da cultura pop. 


\section{REFERÊNCIAS}

ECO, Umberto. Apocalípticos e Integrados - 2a edição. Perspectiva, São Paulo,1974.

LEPORE, Jill. A História secreta da Mulher-Maravilha. Ed. Best Seller, Rio de Janeiro 2017.

NOGUEIRA, Natania. II Guerra Mundial e as "Super-Mulheres :O Surgimento das SuperHeroinas nos Estados Unidos da Década de 1940. In: Representaçóes do Feminino nas Histórias em Quadrinhos. BRAGA, Amaro X.; SILVA, Valéria Fernandes da. (Orgs). Edufal, Maceió, 2015.

VIANA, Nildo; Reblin, Iuri (orgs). Super-Heróis, Cultura e Sociedade: Aproximaçôes multidisciplinares sobre o mundo dos quadrinhos. Ed. Ideias \& Letras, Aparecida, 2011. 